1

2

3

4

5

6

7

8

9

10

11

12

13

14

15

16

17

18

19

20

21

22

23

24

25

26

27

28

29

30

31

32

33

34

35

36

37

38

39

40

41

42

43

44

45

46

47

48

49

50

51

52

53

54

55

56

57

58

59

60

\title{
Disciplinary (Per)Mutations of Ethnography
}

Thomas F. Carter

Head of Centre of Sport, Tourism, and Leisure Studies

University of Brighton

1 Denton Road

Eastbourne BN20 7SR

United Kingdom

+441273641852

t.f.carter@brighton.ac.uk 


\title{
Disciplinary (Per)Mutations of Ethnography
}

\begin{abstract}
There has been a veritable explosion across various disciplines 'discovering' ethnography over the past three decades. This article argues that the proliferation of 'ethnography' outside anthropological circles has led to some pervasive interrelated misconceptions about ethnography, misconceptions reinforced by some of the reflective debates within anthropology. Consequently, this article argues that the broadening interdisciplinary discussions of 'ethnographic methods' obscure the actuality of ethnography. Practitioners in these disciplines often discuss how they employ 'ethnographic methods,' as if these 'methods' are the equivalent of engaging in ethnography. As a result, some rather significant differences in the way disciplines conceive and practice ethnography emerge because of how ethnography itself is conceptualized rather than how it is practiced. Ethnography is not simply an amalgamation of constituent parts; it is a sum greater than its constituent parts. There is more to ethnography than either its methods or its texts. While ethnography is also about the kinds of stories, narratives, and diverse ways in which knowledge is produced and its findings are presented, ethnography is so much more than a literary endeavour. All of the research methods found in ethnography are used in other forms of research, yet said methods, in and of themselves, do not make ethnography unique nor make an ethnography. Ethnography is much larger, profound, and illuminating.
\end{abstract}

Keywords: anthropology, ethnography, fieldwork, knowledge, methodology, ethnographic sensibilities, ethnographic permutations 


\section{Disciplinary (Per)Mutations of Ethnography}

The rum churned leaden waves sloshing in my belly mirror the waves rocking the small, weather beaten boat in which I tensely sit. The rum likely has something to do with my discomfort although the water's choppiness certainly reinforces my uneasy ill feelings. All is dark - no stars or moon and the boat's owner runs no lights. Only the faint, distant coastal town's feeble light causes the periodic whitecaps to glow faintly gold. Otherwise, there is no light by which to see. The owner cuts the outboard motor and we drift on the current.

Our senses strain outward to try and locate ourselves in the world. Each of us seemingly lost in our own head. The older sailor sits at the helm quietly murmuring under his breath. The young man in the prow fidgets, rocks in rhythm to the waves caressing the hull. His hands twitch as he methodically coils and uncoils the anchor rope, staring out at something only he can see. Other than the faint luminosity of wave tips, I see no sensible point of reference beyond our vessel. The three of us are silent in the darkness; the whispering zephyrs and squelching slaps are oddly reassuring. I have no idea where we are or where we are going, much less what is about to happen.

Instead, I am deliberately adrift with two "sailors" - alleged smugglers, handymen, guides, fishermen, dockworkers - I met through a network of socios - trusted friends and their close interpersonal networks. We are not supposed to be out here at night, especially with no lights. Yet here we were, rocking and rolling along with the waves because of a series of loosely connected events that incited me to seek out these men. Our sojourn was all "hush-hush" because, technically, what we were doing is illegal. Cuban fishermen are not supposed to be out at sea at night, not unless they had a factura (license) from the authorities. We weren't fishing anyway. Fishing is not the legal question. The issue is being at sea without permission. We did not leave from a designated harbor, but one of the many 
makeshift retractable jetties that can be put into and taken out of the water. These men, like a lot of working-class rural Cubans, fish to augment their own larders or earn enough to purchase other items on the grey market. The question of legality simply is not a factor in their lives. Illegality is often required in 1990s Cuba if you are to survive no matter who you are. Government official, elite athlete, academic, car owner, restaurant manager, shopkeeper - it does not matter because everyone has to find alternative sources of income outside their state-sanctioned jobs because state salaries no longer meet an individual's basic needs.

In many ways these conditions are emblematic of ethnography itself. The ambiguities of assigning a "role" to these men, the (il)legality of being at sea, and the (un)certainties of life demonstrate a crucial aspect of ethnographic inquiry. Ethnography addresses what we don't know as part of our knowledge production. We may have some idea of what we are looking for in the first place - that is why we go to "the field" after all. But that presumed knowledge is transformed if ethnography is being done well. I had no intention of being in a boat off the north coast of Cuba when planning my fieldwork. The vagaries of fieldwork and the shifting circumstances while I pursued the ethnographic object "Cuban baseball" led me to a makeshift jetty on a relatively calm, cool, overcast winter's night. In acknowledging and addressing the incomplete nature of human knowledge and our very lives, ethnographic research draws out the dialogic choppiness of our knowledge about the world. It tacks between our certainties about our selves and worlds and the uncertainties that surround and penetrate those certitudes. Much, much more than a sympathetic description and subjective analysis of a "culture," at its best, ethnography is an attempt to discern at least part of the lifeworld of a specific group of people and how they live in those worlds.

\section{On Ethnographic Knowledge}


Ethnography is a deeply powerful empirical form of knowledge production precisely because of the ethnographer's entanglement with the object of enquiry (Chung, 2009; Peterson, 2009). It is now a well-worn cliché that knowledge, even that of material things, is socially constructed, mediated and, at best, secondhand. Outside of our narrow specialties, we are all in a position of knowing only what we read (or watch on the internet). Naturally, it would be farcical to put too much stock in those forms of knowledge on their own. Many taken-forgranted concepts are simply ethereal and happen at such incomprehensible scales that they cannot be experienced directly and we therefore mistake their assumption for knowledge. The assertion of ostensibly perfect information produces, more often than not, imperfect, superficial knowledges that have to be discussed as abstractions taken on a necessary degree of faith. Such abstract knowledge is, of course, real and collectively imagined, but because of its very nature, it is extremely difficult to know it as such. Governments, the media and the academy, for related but different reasons, all tend to employ such abstractions as if their meanings were more or less self-evident. This creates a faux-empiricism and an illusory sense of concreteness. We are all too often unaware of the significance of things because our conceptual language simply does not articulate questions that enable us to fathom just what is actually going on. The ability to tease out problematizing questions regarding what we know, as well as the requisite knowledge needed to answer those questions, is the real strength of ethnography.

The recent devaluation of ethnography as a viable form of knowledge production stems from an ascendant neoliberal ideological position that emphasizes an ability to plan and control reality via science-as-technology. Ethnography’s devaluation by think tanks, industry insiders, and policy makers is underpinned by a technical "politics of understanding" that inveigles predictions and pronouncements that never require actual use of knowledge (Luhmann, 1998, p. 69-70). Instead, the function of "experts" in this environment is to 
establish points of discourse and discussion surrounding established "facts" that must be managed by reducing various forms of knowledge to a single quantifiable standard (Merry 2016, p. 27-43). The emphasis on the management of knowledge through a quantifiable process means that ethnography, allegedly, has no practical outcome or "impact" - a grave concern given national funding bodies' recent emphasis on "impact." They fetishize "facts" as discoverable entities existing outside human reality waiting to be found on a seashore rather than engaging with the undulating and oscillating lived human realities from which facts form. Under this authoritarian regime of "expertise," ethnography appears to be irrelevant - transformed from an assertion to an anecdote, or even a mere asterisk, that obliquely supports already known "facts." The neoliberal transformation of universities has reinforced this mutation of ethnography. Even within the discipline, some anthropologists engage in theorizing and philosophizing over "facts" rather than using their field-based experiences to produce their own anthropological knowledge.

Ethnography, however, begins from the position that one is not "authorized" or "expert" within the worlds of the people with whom the ethnographer works. Just because I had "expert" baseball knowledge and skills did not mean that I had the requisite knowledge of baseball as it exists in Cubans' world. My knowledge of baseball reconstituted as I experienced Cuban diamonds and stadia. I had to learn the Cuban way of baseball and through that process, gain an incomplete understanding of what it means to be Cuban (Carter 2008, pp. 159-182). My knowledge garnered from my fieldwork in the 1990s mutated with subsequent fieldwork in the 2000s and in the 2010s precisely because Cubans' epistemological worlds were changing as well. My insistence on long-term study forces me to acknowledge the situatedness of my work. My knowledge as a former player, a white man, and an American citizen all influenced my interactions with everyone there. My position in Cuba was ambiguous since most of the people with whom I worked knew only two kinds of 
foreigners: tourists and journalists. Tourists would disappear after a week or two. I did not disappear, ergo I was a journalist as far as they were concerned, even to those to whom I repeatedly explained what my research was about. Further, the seasons I spent in Cuba were at a time of extreme uncertainty. The political and economic situation was extremely precarious. Another ethnographer studying Cuban baseball today would encounter very different scenes in the stands, on the streets, and very different arguments with fans. Of course, different interlocutors will have different perspectives on the same practice even if approached on the same day and in the same location. The diversity of experiences, interpretations, and continuously changing and shifting ethnographer-participant relations are what constitute ethnography. Because ethnographic knowledge is situated, my own knowledge of Cuba must evolve as well. Not everything I learned in the 1990s is still accurate or even real today. The best ballplayers no longer play in Cuba; they play in the US despite the near-impossibility of legally migrating directly there from Cuba. Our knowledge is situated in specific moments in time and space from specific positions in the field -baseball and ethnographic (Carter, 2011a).

This is how ethnography works. Ethnographic knowledge reconstitutes itself over time. It floats lightly across the surface of people's worlds while probing humanity's depths and, in so doing, offers, not just a different perspective but a more fluid mode of knowing the world. By its very nature, ethnography challenges forms of "expertise" precisely because “expert knowledges" close down questioning and erase other possibilities. Ethnographic inquiry repeatedly demonstrates that the "facts" or "data" are not waiting to be discovered and recorded. They are fictions in the sense that that knowledge is "something made" or " 'fashioned;' not as if they are false, unfactual, or merely 'as if' thought experiments" (Geertz 1973, p. 15-16). Ethnographies are crafted and the materials used and in what combinations how they are "made up"- are of vital importance. 
This does not mean that ethnographic data is not empirical. If anything, the open questioning of the "facts" and their active construction by the researcher is an important aspect of any study. Anthropologists have long insisted that the very "object" of knowledge changes depending on which and whether a statistical relation or a social system of relations is privileged (Westbrook, 2008, p. 103). Similarly, the disciplinary training of the ethnographer affects the kind of ethnography produced. This is hardly surprising given that each discipline approaches the ethnographic subject from different ontological perspectives.

To illustrate, consider three widely acclaimed ethnographies on the marginalized, urban poor conducted in Philadelphia (Goffman, 2014), Chicago (Venkatesh, 2008), and in New York (Bourgois, 1996). Each ethnographer's ethnicity, gender, discipline, and nationality differs from the other two, yet all three (re)produce the same tropes despite their ethnographies' geographic and temporal differences. Nonetheless, the disciplinary ontology produces subtly different kinds of ethnographic knowledge. The sociologists, Goffman and Venkatesh, focus more on the determinant social structures of family, police, community, and gang shaping their interlocutors' lives. Police and law enforcement encounters fuels Goffman's classificatory account of "clean" and "dirty" lives, therein reinforcing her collaborators' inability to transcend the forces shaping their lives. Venkatesh recounts how gang-life and organizational structure mirrors the corporate world, even taking on the role of “CEO" by becoming a gang leader for one day. The two inadvertently reify the structural conditions of their marginalized subjects rather than demonstrate how residents' build their own lives and situated knowledges as Bourgois does in his ethnography on how the dealers and users of East Harlem make their lives and worlds in spite of, rather than because of, the oppressive institutionalized domination that marginalizes these urban populations: For Bourgois, the police are there offstage whereas they are active characters in Goffman and Ventakesh's ethnographies. 
These three ethnographies make it abundantly apparent that ethnography captures the contradictions found in the vagaries of impersonal power that shapes individuals' everyday lives. They all challenge the dominant neoliberal political orthodoxy about individual selfresponsibility within a "free market" through their implicit comparison of "white middleclass Americans" whose lives in the formal economy are as different from these marginalized Americans as the lives of Trobriand islanders are to European ethnographers. "No good ethnography is self-contained. Implicitly or explicitly ethnography is an act of comparison" (Sahlins, 1993, p.10). Ethnography is inherently comparative but the kinds of comparison an ethnography makes depends on one's disciplinary training.

All social science disciplinary forms of knowledge include what human beings do as part of their endeavors but only anthropology places homo sapiens as its explicit object of enquiry and its principal emphasis on the myriad ways we become human beings.

Ethnographies on the same subject will differ depending on the ontological base of the study. This broader, more holistic approach distinguishes anthropological ethnography from other forms of ethnography even as the relationship between ethnography and anthropology has become increasingly problematic. The assertion that "ethnography is anthropology or it is nothing" (Sahlins, 1993, p. 10) no longer holds water. But "if ethnography is not a means to an end in anthropology, then neither is anthropology the servant of ethnography" (Ingold, 2008, p. 88). For ethnography is recursive: ethnography's contents change through the contexts in which that research is conducted. Our misapprehensions and misunderstandings inform our investigative tools and disciplinary compass so we can generate the possibility of new concepts by bringing previously unrelated ones into relationships that mutually modify the meanings of the concepts involved (Holbraad, 2012, pp. 252-3).

That ethnography and anthropology are not symbiotically beholden to one another is hardly a surprise to anyone outside anthropology. Ethnography today is just as likely to be 
claimed as a practice in art and design studios, by education professionals, or by health practitioners as it is by anthropologists. However ethnography is practiced, that practice is a craft and to be a craftsperson represents the condition of being engaged (Sennet, 2009, p. 20). Like all crafts, ethnography requires long, skillful practice, and all skills begin, if not continue, as bodily practices. It is through these bodily practices in the field that the technical understanding of ethnography develops. While individual skills (i.e. methods) can be taught and trained, it is through their combined implementation in a specific context-laden field that ethnographic craft begins to germinate. Ethnography is not a rote-training program of steps or sequential skills developed but a honing of field-based investigative skills practiced on a regular basis in specific contexts. These skills, of course, can be learned by anyone. The craft of ethnography, however, depends on the nature of fieldwork and the disciplinary framing of one's epistemological practices. These differences are what lead to distinct notions of ethnographic research and writing: i.e., ethnographic sensibilities.

\section{Ethnographic Sensibilities}

One reason why the relationship between anthropology and ethnography has become strained in recent decades is that what is meant by fieldwork has undergone major transformations. From anthropology's very beginnings, the constitution of fieldwork was a central question (Barth et al, 2005; Stocking, 1981). The Polish anthropologist Bronislaw Malinowski invented what now is recognized as the basic tenets and practices of ethnography, insisting that one must get off the verandah, live amongst the people being studied, interact with them in their own language, and concentrate on the everyday minutiae of their lives (1961[1922], pp. 2-25). This logic privileges direct observation conducted in a remote site, a notion that along with the colonially veiled constitution of civilized and savage- constructs the archetypical fieldworker as a Euro-American, white, middle-class man. Fieldwork thus 
became synonymous with a heroic quest into Others' territory, a trope that engendered and cemented Malinowski's mythopoetic charter of modern ethnography (Stocking, 1992; cf. Clifford, 1988).

Ethnography, of course, changed throughout the twentieth century as paradigmatic shifts occurred throughout the social sciences, including anthropology. These shifts occurred because of the global shifts in power and our interlocutors' growing resistance to the traditional forms of fieldwork. Ethnographers can no longer assume that they are free to enter (and leave) people's lives as they please. Of course, this shift occurred not only because of anthropology's self-critique, but because the people with whom we work have been pushing back now for decades. Nor is ethnography tied to a singular geographic location. With the advent of multi-sited ethnography associated with the analysis of global flows, of digital ethnography and of the ethnography of online social media, "being in the field" is no longer a sense of embodied co-presence but a recognition that spatial proximity is not a requirement for meaningful human relationships. How humans relate to their surroundings and build their relationships are a central part of their worlds. Recent, powerfully evocative anthropological ethnographies detail these relations that exist without shared physical spaces, or even material bodies (Boellstorff, 2008; Coleman, 2015) for that matter, making it apparent that the relations that make any one of us human may not be comprised of intensive face-to-face interactions bounded within a singular unit but an unbounded kaleidoscopic mosaic of relationships that forms a Self.

During the first two-thirds of the twentieth century, the unit of analysis in anthropology was a "culture" that existed as a discrete, whole universe. In the past few decades, however, anthropological sensibilities evolved considerably from the study of "a culture" to a form of cultural critique (Marcus and Fischer, 1986), of engagement or encounter (Marcus, 1998), or of design (Rabinow et al, 2008). Anthropologists debated 
whether the concept of culture was even useful (Fox and King, 2002; Ortner, 1999). In the twenty-first century, anthropologists have taken the concept of culture in new directions. Recent ethnographies conceptualize culture through imaginaries (García Canclini, 2014), intersubjectivities (Kohn, 2013) assemblages (Ong and Collier, 2004), and as emergence (Tsing, 2015). Additionally, some ethnographically-based metaphysical introspection on culture has challenged the previously taken-for-granted division between nature and culture leading to a wide ranging debate as to how to conceptualize culture when it becomes the constant and nature is relativistic (Viveiros de Castro, 2015; cf. Piña-Cabral, 2015) even as others debated whether culture is the equivalent of ontology (Carrithers et al. 2008). While these debates remain unresolved, ironically, culture is no longer the unquestioned ontological object of the discipline even as it became an increasingly important object in other disciplines. Thus, anthropology's continuing uncertainties surrounding its central ontological object of enquiry also leads to methodological quandaries. These disciplinary selfflagellations continue as anthropology evolves and central to these disciplinary worries is the nature of ethnography and how it shapes the production of anthropological knowledge.

Amongst these worries about ethnography's (per)mutations are the changing conceptions of fields and conducting fieldwork. It has long been customary to divide ethnography into three distinct practices: that of observation, description, and comparison. These operations, however, are not discrete stages but intertwined activities that are not readily separable. One cannot say easily where, when or how one ends and the other begins. Furthermore, in anthropology, these distinctions were based on spatial distinctions - "going to", "being in", and "returning from" the field -that shaped field practices, making ethnography akin to that mythopoetic quest identified earlier. But a spatial circumscription of the field is no longer tenable. This spatial determinism was dismantled in anthropology twenty years ago (Amit, 2000; Gupta and Ferguson, 1997). The rise of globalization, 
transnationalism, and other macroscale processes linking discontiguous localities forced a reconsideration of anthropology's core practices. Now, it is best if the field is conceptualized as a confluence of various forces enmeshing the ethnographic object of enquiry (Carter, 2011a; Marcus. 1998). My presence in that boat was my early recognition that the spatial solidity of Cuba was my own misapprehension of the field. Cuba floats on currents that alter its composition (Carter 2008, p. 36). It does not end where land meets sea. That sea excursion captured a small sense of what trafficked athletes felt as they try to leave the country clandestinely (Carter 2011b, p. 152-179). By going to sea for a few hours in this manner, my own tense nervousness, heightened precariousness, and acute vulnerability transformed my understandings about Cuban baseball, Cubans, Cuba, and how to do ethnography.

An alternative approach shifts the focus onto fieldwork's temporalities despite endemic temporal distancing in early anthropological ethnography (Fabian, 1983). Time remains a challenge in terms of fieldwork. "The ethical profile of the good anthropologist yields no methodological a priori concerning the appropriate duration of a project. Everything hinges on the terms and conditions of the question of research itself' (Faubion 2009, p. 163). The critical practice of anthropological fieldwork is typically long, often meandering, inescapably social, and temporally situated. It demands a critical social awareness that multiple, different temporalities might be at play simultaneously (Malkki 2007, p. 177). Ethnography's transdisciplinary temporal mutations call into question the very notion of what constitutes fieldwork. Long-term engagement in a field is increasingly problematic because of the political reframing of what constitutes knowledge. The substance of ethnography requires an engagement with these temporal permutations even as anthropologists acknowledge that any ethnographic object is not fully accessible. Anthropologists continue to produce intensely, intensively, and locally salient knowledge even as ethnography has mutated from clearly defined coterminous objects and fields into increasingly problematized, 
multiply variable objects and fields. The irony is that anthropologists do not become known for being good fieldworkers but occasionally do become recognized for being good ethnographers.

The simple realization that a good fieldworker is not ipso facto a good ethnographer raises a second aspect of anthropological unease with ethnography's travels. Ethnography mutates as it crosses disciplinary boundaries because each discipline has its own a priori ontological object, whether that object is "society" (sociology), "health" (medicine), "space" (geography), "mind" (psychology) or "culture" and "subculture" found in a range of interdisciplinary fields (cultural studies, sport studies, media studies, leisure studies and so forth), underpinning the ethnographer's default position. These different ontological certainties are not, in and of themselves, a problem. However, the move towards ethnography as critique, encounter, or design thins the resonant depths of ethnography as knowledge. The conflation of methods and methodology in particular makes the thinning of ethnography worrisome.

\section{Ethnographic (Per)Mutations}

Within anthropology there is no such thing as "ethnographic methods." Ethnography is not a set of formal procedural means designed to satisfy the ends of inquiry. Ethnography has a particular philosophical stance towards phenomena, including taking a particular disposition towards the world and thus asking certain kinds of questions about phenomena, produces its own knowledge, and disseminates that knowledge in specific forms of exposition.

Ethnographers make use of a range of methods: participant observation, interviews, film, audio recordings, printed materials, social media, and more. Thus, ethnography is a methodology - that is, a specific way of doing research and producing knowledge about our world in which the researcher engages with the limits of one's own knowledge. 
The question of whether an ethnographer can truly be a good ethnographer if one transgressed certain boundaries was an ongoing concern in twentieth-century anthropology: first as a worry about "going native" and then whether a "native anthropologist" could maintain "objective" or "critical" distance because of one's personal life history. Such concerns over the positionality and voice of "native" ethnographers are misguided and misplaced (Narayan, 1993; Jacobs-Huey, 2002). By the logic of this solipsistic categorization, I was a native ethnographer of baseball given that I had spent my entire life engaged in the practice prior to conducting my fieldwork on the topic yet I was obviously not a Cuban. Of course, my lifetime's experience of baseball necessitated a critical reflexive engagement of my own embodied knowledge compared with how Cubans understood the same physical acts involved in playing the sport but that in no way meant I could not do so. The motions may have looked the same. I knew what to do but not necessarily why to do it in a certain way. I could not presume the emotions and meanings of those physical acts were what I "knew" they were "supposed" to feel and mean. Ideally, an ethnographer will have some working knowledge of the practices and processes being investigated; however, even with a degree of expertise, there can be no presumption that the ethnographer knows how others embody skills and knowledge.

Similarly, one cannot be assured of one's competence as an ethnographer, never mind as a fieldworker, simply by mastering a known set of methods despite the various methods textbooks on ethnography. The vast array of field methods -- from interviews and observation, to life histories, mapmaking, photography, archival work, and myriads more are all possible techniques in open, flexible, time-dependent, context-dependent possibilities. Many ethnographers also need to develop specific physical skills that do not necessarily transfer from one field context to another. For example, fieldwork I conducted in Cuba during the 1990s relied upon my skills and knowledge that I had accumulated in my youth as 
a relatively skilled baseball player. While that set of physical skills and bits of esoteric knowledge of baseball trivia served me well while studying the spectacle of Cuban baseball (Carter, 2008), the ability to pitch a baseball actually hindered me on the cricket pitch in Northern Ireland where I found the embodied skill of bowling (a different form of throwing than pitching) utterly impossible (Carter, 2003). These embodied practices require sensory as well as sensorimotor skills: one has to learn how to see, taste, and otherwise sense the world in the way the ethnographer's collaborators do (Pink, 2009; Stoller, 1989). Yet there are, to my knowledge, no dedicated training tools to learn to sense the world in a different lifeworld. The only means I know of is immersion in that lifeworld in which long-term, in-depth interactions are conducted in a way that permits collaboration between ethnographers and their consultants.

The range of tools available to the ethnographer, therefore, cannot be a closed set of procedures. Ethnography's open-endedness is partly why it, especially anthropological ethnography, is so difficult to teach in a standardized manner from a textbook. Generally, anthropologists have avoided attempting to write any such manual. The widely respected manuals used outside anthropology to instruct "how to do ethnography" are barely touched within the discipline because of the anthropological sensibility that ethnography is not a set of standard or universally applicable methods.

Of course, anthropology has its methods, but ethnography is not one of them: ethnography is a methodology. The idea of an "ethnographic method" is a transdisciplinary mutation invoked when something else is meant entirely. The emergence of this term appears to be a part of the transdisciplinary discussions around "mixed methods" that treat ethnography as one of several means of gathering data, again as if ethnography was reducible to a form of gathering information. In this vein, "ethnographic methods" is often conflated with a combination of participant observation and interviews. Observation, participant 
observation, and interviews are methods and these can be mixed in a range of combinations, but that mixture is not the equivalent of ethnography. These and all of the other research methods deployed in ethnography are used in other forms of field research. None of the methods used to produce ethnography are unique to ethnography, make ethnography distinct, nor make an ethnography. One can use any or all of these tools without actually conducting ethnography. "Nothing has been more damaging to ethnography than its representation under the guise of "ethnographic method"' (Ingold, 2008, p. 88). There is insufficient space to conduct an archaeological exercise into when and how ethnography came to be considered one qualitative method among many, though I suspect that the traversing of disciplinary boundaries plays a significant factor in such a conceptual shift from methodology to method.

Part of the challenges found in ethnography's mutations are due to the already established notions of fieldwork in other disciplines. Ethnographic fieldwork differs from other forms of fieldwork because the researcher cannot know in advance how to do it and what will be found because of the open-ended nature of ethnographic enquiry. In anthropology, this is especially acute, given that anthropology's focal point is the ways in which people actually live their lives in their specific lifeworlds. Most often, an ethnographer attempts to provide what it might be like to experience the world in other terms of reference, through other sensibilities, to be shaped by different emotional frameworks, and to live by different logics of being. In effect, ethnographers attempt to make the strange familiar and the familiar strange. Those worlds are, more often than not, alien worlds unfamiliar to the aspiring ethnographer. Even when there is a long personal history with the ethnographic subject, the ethnographer's critical positionality allows the exploration of the conundrums, contradictions, and ironies of contemporary lives. The conscious distancing of one's own critical practice ensures that what would otherwise just be considered "normal" is reflexively poked, prodded, and probed. The notion of a "native" ethnographer is moot, for each 
ethnographer will bring their own sets of knowledges to the field. It is what the ethnographer does with one's own knowledge that matters. One either does ethnography or one does not. There is no middle way.

\section{Conclusion: Ethnographic Currents}

To engage well in ethnography is to recognize how a singular phenomenon opens up the deeper one delves into it. There is an unfolding rather an encompassment of the ethnographic object by the world. Ethnography remains central to anthropological practice because it is still the best way to capture the diversity of human life in all its magnificence while also stripping away the deceptions people impose on themselves and others. It allows us to find our ways when we are sailing in the dark.

This article began with me being all at sea, uncertain about my very existence, realizing that I knew very little about my immediate world including where in that world I was. It was alien, frightening, and nerve wracking and essentially captures the feelings of conducting ethnography precisely because the manner in which one conducts ethnography requires an awareness of the ways in which one does and does not understand the world. Working in an interdisciplinary department reinforces my own experience of how ethnographic currents travel across disciplines, with certain aspects staying afloat while others are jettisoned into inky depths as scholars from a range of disciplines claim ethnography as their own. Different disciplines possess very different sensibilities and ontological objects and these clearly affect the kinds of ethnography that can be conducted and the forms of ethnographic knowledge that can be produced. The anthropological ethnographer attempts to understand how humans, in contemporary circumstances, construct worlds that allow them to function, and what their practices might mean for the rest of us. How we choose to engage and deal with our world, the currents of meaning we make out of 
what happens to us and what we do to each other to enact our world, should be the focus of ethnographic enquiry. Because the world itself is continuously evolving and changing, so too must ethnography.

This article mirrors the very incompleteness of ethnography. Ethnography continues to change in its conception and practice. Fieldwork is losing its spatial parameters, the ethnographic object of enquiry can only ever be engaged in a partial manner, and ethnographic knowledge can only ever be incomplete. These conditions are hardly weaknesses of ethnographic knowledge. Ethnography's choppiness - its discomfiting sensations of uncertainty and its only ever partial knowledge - is what makes it compelling. Many of the points raised here may feel incomplete, partial, and like there are no final, definitive answers, which so happens to be exactly what ethnography should feel like: raising uncertainties in our certitudes. My stomach still churns every time I return to Cuba.

The helmsman restarts the engine on the second pull after flicking his cigarette into the water. Its acrid smoke clings to us as he turns the prow toward a darker blotch of blackness. I've learned how disorienting being at sea with no lights can be but I really haven't captured what the sense of risking one's life in such a manner must be like, which was the reason I persisted with my socios to introduce me to Cubans who could take me out to sea. In hindsight, putting out to sea in that context was a damn foolish risk to take. I was the instigator, I fashioned the circumstances by searching out those two sailors through my socios' networks. They did not have to help me but without their help I never would have met those two sailors. And those two men did not have to accept my overtures to do something that many of my socios considered to be the height of lunacy. We all took risks - differently loaded and (mis)understood - based on our individual knowledge and judgements. My knowledge of being at sea in darkness is inchoate, incomplete and inconclusive. The ways in 
which human beings deal with ambiguities, uncertainties, and unknowns that inform life is what makes ethnography so powerful and important. 


\section{References}

Amit, V. ed. (2000). Constructing the field: Ethnographic fieldwork in the contemporary world. London: Routledge.

Barth, F., Gingrich, A., Parkin, R., \& Silverman, S. (2005). One discipline, four ways: British, German, French, and American anthropology. Chicago: University of Chicago Press.

Boellstorff, T. (2008). Coming of age in second life: An anthropologist explores the virtually human. Princeton: Princeton University Press.

Bourgois, P. (1996). In search of respect: Selling crack in El Barrio. Cambridge: Cambridge University Press.

Carrithers, M., Candea, M., Sykes, K., \& Holbraad, M. (2008). Ontology is just another word for culture. Critique of Anthropology, 30(2): 152-200.

Carter, T. F. (2003). In the spirit of the game? Cricket \& changing notions of being British in Northern Ireland. Journal for the Society of the Anthropology of Europe, 3(1): 14-26.

Carter, T. F. (2008). The quality of home runs: The passion, politics, and language of Cuban baseball. Durham: Duke University Press.

Carter, T. F. (2011a). Considering the field in and of play: Using sport to reconceptualize an anthropological given. In P. Collins \& S. Coleman (Eds.) Dislocating anthropology? Bases of longing and belonging in the analysis of contemporary societies (pp. 63-80.) Newcastle: Cambridge Scholars Publishing.

Carter, T. F. (2011b). In foreign fields: The politics and experiences of transnational sport migration. London: Pluto Press.

Chung, J. (2009). Ethnographic remnants: Range and limits of the social method. In J. Faubion \& G. Marcus (Eds.) Fieldwork is not what it used to be: Learning 
anthropology's method in a time of transition (pp. 52-72). Ithaca: Cornell University Press.

Clifford, J. (1988). The predicament of culture: Twentieth century ethnography, literature, and art. Cambridge: Harvard University Press.

Coleman, G. (2015). Hacker, hoaxer, whistleblower, spy: The many faces of Anonymous. London: Verso.

Fabian, J. (1983). Time and the Other: How anthropology makes its object. New York: Columbia University Press.

Faubion, J. (2009). The ethics of fieldwork as an ethics of connectivity, or the good anthropologist (isn't what she used to be). In J. Faubion \& G. Marcus (Eds.) Fieldwork is not what it used to be: Learning anthropology's method in a time of transition (pp. 145-166). Ithaca: Cornell University Press.

Fox, R. G., \& King, B. J. (Eds.). (2002). Anthropology beyond culture. Oxford: Berg. García Canclini, N. (2014). Imagined globalization. Durham: Duke University Press. Geertz, C. (1973). The interpretation of cultures: Selected essays. New York: Basic Books.

Goffman, A. (2014). On the run: Fugitive life in an American city. Chicago: University of Chicago Press.

Gupta, A. \& Ferguson J. (Eds.). (1997). Anthropological locations: Boundaries and grounds of a field science. Berkeley: University of California Press.

Holbraad, M. (2012). Truth in motion: The recursive anthropology of Cuban divination. Chicago: University of Chicago Press.

Ingold, T. (2008) Anthropology is not ethnography. Proceedings of the British Academy, 154: 69-92. 
Jacobs-Huey, L. (2002). The natives are gazing and talking back: Reviewing the problematics of positionality, voice, and accountability among 'native' anthropologists. American Anthropologist, 104(3): 791-804.

Kohn, E. (2013). How forests think: Towards an anthropology beyond the human. Berkeley: University of California Press.

Luhmann, N. (1998). Observations on modernity. Stanford: Stanford University Press.

Malinowski, B. (1961[1922]). Argonauts of the western pacific. New York: E.P. Dutton.

Malkki, L. (2007). Tradition and improvisation in ethnographic field research. In A. Cerwonka \& L. Malkki. Improvising theory: Process and temporality in ethnographic fieldwork (pp. 162-187). Chicago: University of Chicago Press.

Marcus, G. (1998). Ethnography through thick and thin. Princeton: Princeton University Press.

Marcus, G. \& Fischer, M. (1986). Anthropology as cultural critique: An experimental moment in the human sciences. Chicago: University of Chicago Press.

Merry, S. E. (2016). The seduction of quantification: Measuring human rights, gender violence, and sex trafficking. Chicago: University of Chicago Press.

Narayan, K. (1993). How native is a 'Native' anthropologist? American Anthropologist, 95(3): 671-686.

Ong, A., \& Collier, S. (Eds.). (2004). Global assemblages: Technology, politics and ethics as anthropological problems. London: Blackwell.

Ortner, S. (1999). The fate of 'Culture': Geertz and beyond. Berkeley: University of California Press. 
Peterson, K. (2009). Phantom epistemologies. In J. Faubion \& G. Marcus (Eds). Fieldwork is not what it used to be: Learning anthropology's method in a time of transition (pp. 37-51). Ithaca: Cornell University Press.

Piña-Cabral, J. de (2015). World: An anthropological examination. Chicago: Hau Books.

Pink, S. (2009). Doing sensory ethnography. Los Angeles and London: SAGE.

Rabinow, P., Marcus, G., Faubion, J. \& Rees, T. (2008). Designs for an anthropology of the contemporary. Durham: Duke University Press.

Sahlins, M. (1993). Waiting for Foucault, still. Chicago: Prickly Pear Press.

Sennett, R. (2009). The craftsman. London: Penguin.

Stocking, G. W. (1981). Observers observed: Essays on ethnographic fieldwork. Madison: University of Wisconsin Press.

Stocking, G. W. (1992). The ethnographer's magic and other essays in the history of anthropology. Madison: University of Wisconsin Press.

Stoller, P. (1989). The taste of ethnographic things: The senses in anthropology. Philadelphia: University of Pennsylvania Press.

Tsing, A. L. (2015). The mushroom at the end of the world: On the possibility of life in capitalist ruins. Princeton: Princeton University Press.

Venkatesh, S. (2008). Gang leader for a day: A rogue sociologist crosses the line. London: Penguin Books.

Viveiros de Castro, E. (2015). The relative native: Essays on indigenous conceptual worlds. Chicago: Hau Books.

Westbrook, D. (2008). Navigators of the contemporary: Why ethnography matters. Chicago: University of Chicago Press. 